\title{
QUALITATIVE AND QUANTITATIVE MICROMORPHOLOGICAL INVESTIGATIONS OF THE TERTIARY FOLLICLE POPULATION DURING THE OESTROUS CYCLE IN SHEEP
}

\author{
A. BRAND AND W. H. R. DE JONG \\ Clinic of Veterinary Obstetrics and Gynaecology, \\ University Centre "De Uithof", Utrecht, The Netherlands
}

(Received 3rd May 1972)

\begin{abstract}
Summary. This study describes a quantitative micromorphological investigation of the tertiary follicle population in the ovaries of thirtythree normal cycling Texel ewes. The ovaries were serially sectioned at $10 \mu \mathrm{m}$ and every section was examined.

A pair of ovaries contained an average \pm S.E. of $84 \cdot 2 \pm 38 \cdot 1(32 \cdot 2 \%)$ normal and $177 \cdot 1 \pm 103.4(67.8 \%)$ atretic tertiary follicles. Each ewe had $3.6 \pm 2.8$ normal and $8.7 \pm 4.9$ atretic follicles with a diameter greater than $2 \mathrm{~mm}$. Of the normal tertiary follicles, $82.7 \%$ had a diameter of less than $1 \mathrm{~mm}$.

During the cycle, two growth waves of follicles $\geqslant 1 \mathrm{~mm}^{3}(\stackrel{\infty}{=} 2 \mathrm{~mm}$ in diameter) occur. The first was seen from Days 1 to 10 , the second from Day 6 of one cycle to Day 1 of the next. At the end of the first growth wave, there was only one large follicle per ewe whereas at the end of the second wave, usually two were found. The last follicle of the first wave disappeared by atresia and the last one(s) of the second wave by ovulation. It is suggested that the cyclical changes in progesterone level play an important rôle in the growth pattern of follicles $\geqslant 1 \mathrm{~mm}^{3}$ in volume in both growth waves.
\end{abstract}

\section{INTRODUCTION}

During the oestrous cycle, endocrinological as well as morphological changes occur in the ovaries. According to Quinlan \& Maré (1931), Robertson \& Hutchinson (1962) and Hutchinson \& Robertson (1966), preovulatory follicles in sheep develop rapidly at the beginning of the cycle but increase in volume only slowly during dioestrus. The largest increase in volume was observed at the end of the cycle. In 1934, Grant had already suggested that these follicles could undergo atresia which was not observable macroscopically. Smeaton \& Robertson (1971) followed the growth and atresia of individual Graafian follicles in vivo, and suggested that there were at least three phases of follicular growth and atresia during the oestrous cycle.

The purpose of the present study was to investigate microscopically the 
pattern of development of tertiary follicles, both qualitatively and quantitatively, during the oestrous cycle of sheep.

\section{MATERIALS AND METHODS}

A group of thirty-nine maiden Texel ewes, aged $1 \frac{1}{2}$ years, with normal oestrous cycles (17 days in length) was used. Oestrus was detected by nine raddled fertile rams fitted with 'aprons' During a period of 3 weeks, the rams were put with the flock every $2 \mathrm{hr}$.

The ewes were slaughtered at different stages of the cycle; the ovaries were removed from the carcasses as soon as possible after slaughter, weighed, examined macroscopically and fixed in Bouin's fluid. The fixed ovaries were dehydrated with alcohol, cleared with methyl benzoate and benzol, embedded in Paraplast and sectioned serially at $10 \mu \mathrm{m}$. Most of the sections were stained with haematoxylin and eosin but some with Gieson's stain or by the Azan or periodic acid-Schiff procedure.

In thirty-three ewes, the diameter of all tertiary follicles was calculated by counting the number of sections in which each was observed. In six ewes, the follicular diameter was recorded only when it equalled or exceeded $2 \mathrm{~mm}$. The follicles were grouped according to their diameters into four classes, $<0.5 \mathrm{~mm}$, 0.5 to $1 \mathrm{~mm}, 1$ to $2 \mathrm{~mm}$ and $\geqslant 2 \mathrm{~mm}$, and each of these classes was further subdivided into normal (non-degenerative) and atretic follicles. The following criteria were used as indicators of early or initial atresia in tertiary follicles: (1) loosening and degeneration of the granulosa cells lining the antrum; (2) hyperchromatosis of the nuclear membrane and pycnosis of the granulosa cell nuclei (P1. 1, Fig. 1); (3) local interruption of the membrana propria and disorientation of the basal granulosa cells, together with invagination of thecal tissue into the membrana granulosa (Pl. 1, Fig. 2).

Other indications of atresia found in combination with the above were: (4) a decrease in the thickness of the membrana granulosa layer, with the exception of the cumulus oophorus; (5) absence of mitotic activity in the membrana granulosa, with the exception of the cumulus oophorus; $(6)$ irregularly shaped nuclei in the granulosa cells. The presence of Call-Exner bodies in the membrana granulosa was not considered to be an indication of atresia, since these bodies were present in both atretic and normal follicles.

Two forms of more advanced atresia (obliterative and cystic) were also

\section{EXPLANATION OF PLATE 1}

Frg. 1. Early atresia in the membrana granulosa of a sheep follicle. Some granulosa cells are degenerating, leaving nucleoli and clumped chromatin (A) as 'atretic bodies'. $\mathrm{H} \& \mathrm{E}$ stain. $\times 400$.

FIG. 2. The wall of a sheep follicle in the earliest state of recognizable atresia. Note the indistinct or definitely broken membrana propria (MP) and loss of orientation of the basal layer of the membrana granulosa. Theca interna (TI) cells extend inwards. Note also an adjacent normal follicle. $H \& E$ stain. $\times 100$.

FIg. 3. Obliterative atresia in a tertiary follicle $(2 \mathrm{~mm})$ of a ewe. Note the light folding of the membrana granulosa. $\mathrm{H} \& \mathrm{E}$ stain. $\times 10$.

Frg. 4. Cystic atresia in a large tertiary follicle $(7 \mathrm{~mm})$ of a ewe. Note the remaining granulosa cells arranged as a 'string of beads'. $H$ \& E stain. $\times 250$. 


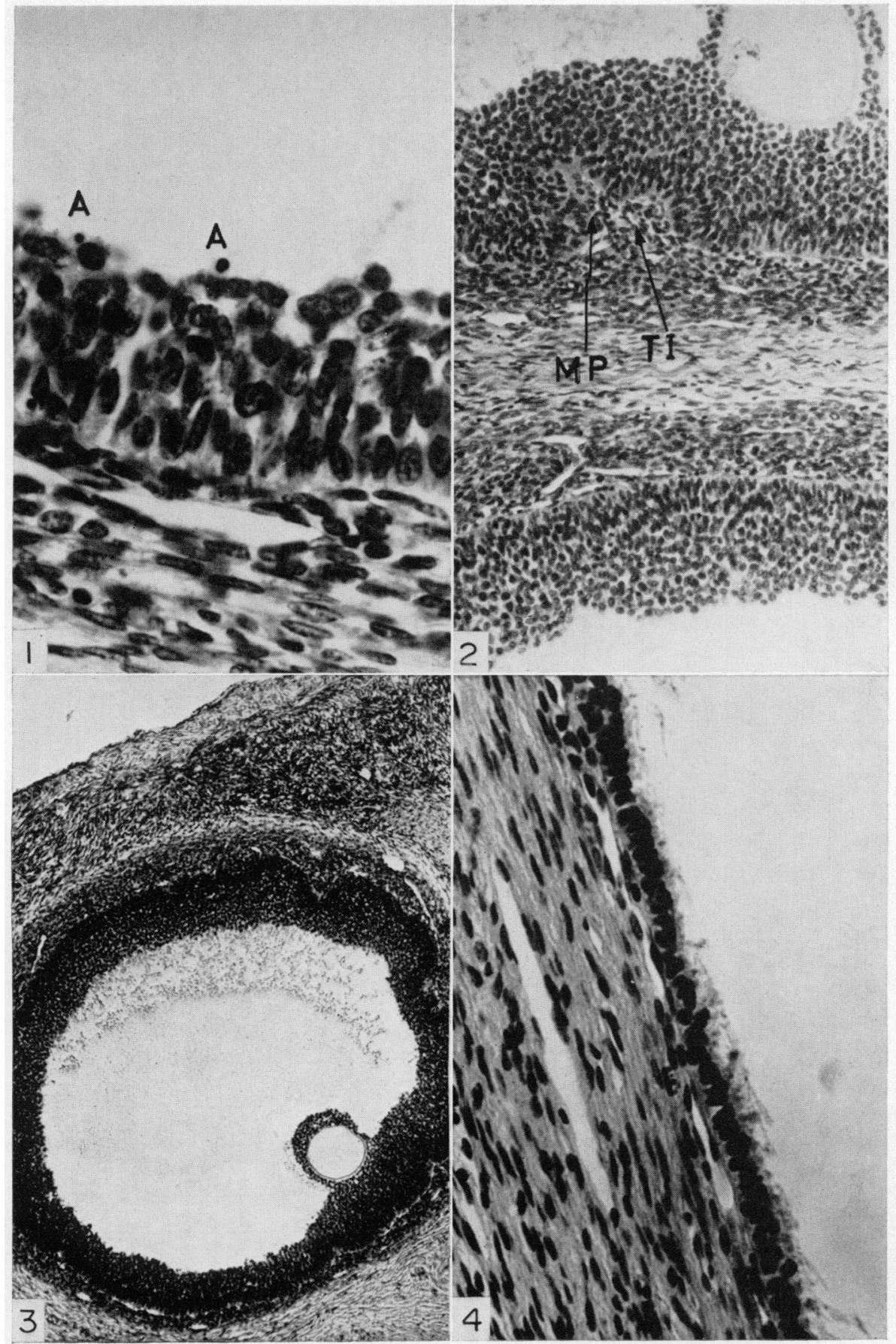

(Facing p. 432) 
distinguished. Obliterative atresia occurred in follicles of up to 3 to $4 \mathrm{~mm}$ in diameter, and was characterized by primary dehydration and folding of the follicular wall (Pl. 1, Fig. 3). Cystic atresia of large follicles was characterized by a thinning and stretching of the follicular wall. The remaining granulosa cells frequently showed a 'string of beads' configuration (Pl. 1, Fig. 4). In the terminal stage of atresia, there was no difference between the two forms and follicular volume was markedly reduced. During further shrinkage of the follicles to a diameter of less than $1 \mathrm{~mm}$, a hyaline membrane appeared round the follicular remnants.

All atretic tertiary follicles were subdivided into three stages of atresia (first, second and third degree) corresponding to initial, advanced and terminal follicular atresia.

In order to compare the size of large follicles more accurately on different days of the cycle, volumetric measurements were made of all follicles larger than $2 \mathrm{~mm}$ in diameter. For this purpose, the formula $\mathrm{V}=\frac{3}{4}$ O.d was applied, in which $\mathrm{V}=$ the volume, and $\mathrm{O}=$ the average follicular surface at one-third and two-thirds of the already known diameter, $d$. The follicular surfaces in the sections were calculated according to the formula for an ellipse, since almost all the follicles showed this form.

The absolute and relative numbers were submitted to an analysis of variance test.

\section{RESULTS}

\section{Absolute frequency distribution}

The size and numbers of normal and atretic follicles on each day of the cycle studied are shown in Table 1 . There was great variation in the total and relative numbers of normal and atretic follicles in the thirty-three ewes investigated. The mean number of tertiary follicles per ewe was 261.3 (figures are given in round numbers), $84.2(32.2 \%)$ of these being classified as normal and $177 \cdot 1$ $(67.8 \%)$ as atretic. Of the normal tertiary follicles, $82.7 \%$ had a diameter of less than $1 \mathrm{~mm}$. For the atretic follicles, this percentage was $80 \cdot 7$. Of the atretic follicles, $24 \cdot 0(13.6 \%)$ showed first degree, $27 \cdot 8(15 \cdot 7 \%)$ second degree and $125 \cdot 3$ $(70.7 \%)$ third degree atresia. The results show there were about twice as many atretic follicles per sheep as normal ones (Table 1).

The mean percentages of normal and atretic tertiary follicles per ewe on various days of the cycle are shown in Text-fig. 1 .

Statistical analysis revealed that during the cycle there was no systematic significant variation in the absolute or relative numbers of normal and of atretic tertiary follicles. This was also true when the follicles were subdivided into classes according to size or according to stage of atresia ( $P$ always $>0.5)$.

Atresia of the first degree was seen most often in follicles with a diameter of 1 to $2 \mathrm{~mm}$; second degree atresia was most common when the follicular diameter was 0.5 to $1 \mathrm{~mm}$ and third degree atresia when the diameter was less than $0.5 \mathrm{~mm}$. This indicates that, in general, normal tertiary follicles reach a diameter of 1 to $2 \mathrm{~mm}$ before becoming atretic.

The absolute numbers of normal and atretic tertiary follicles of the various size classes did not differ significantly between left and right ovaries. 


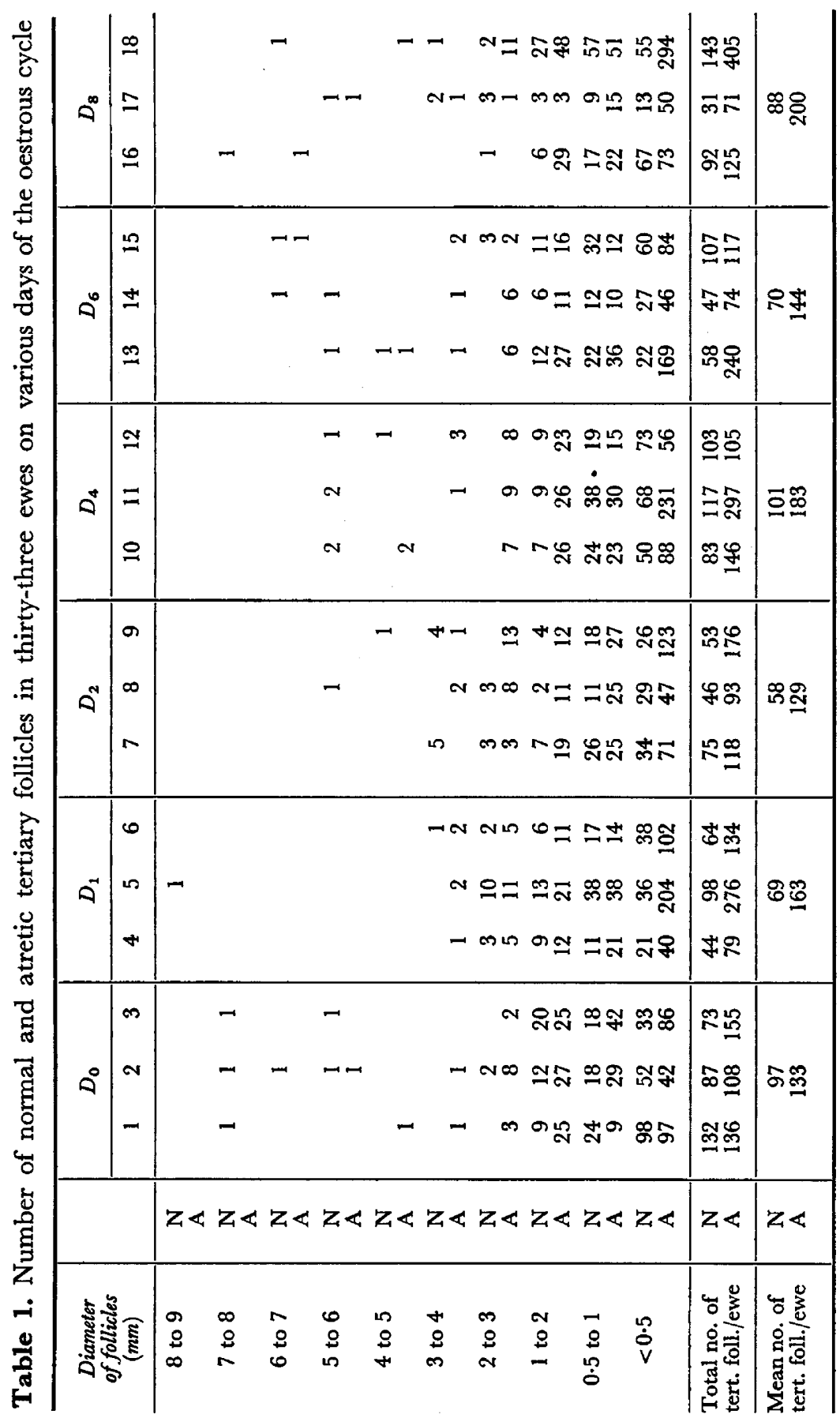




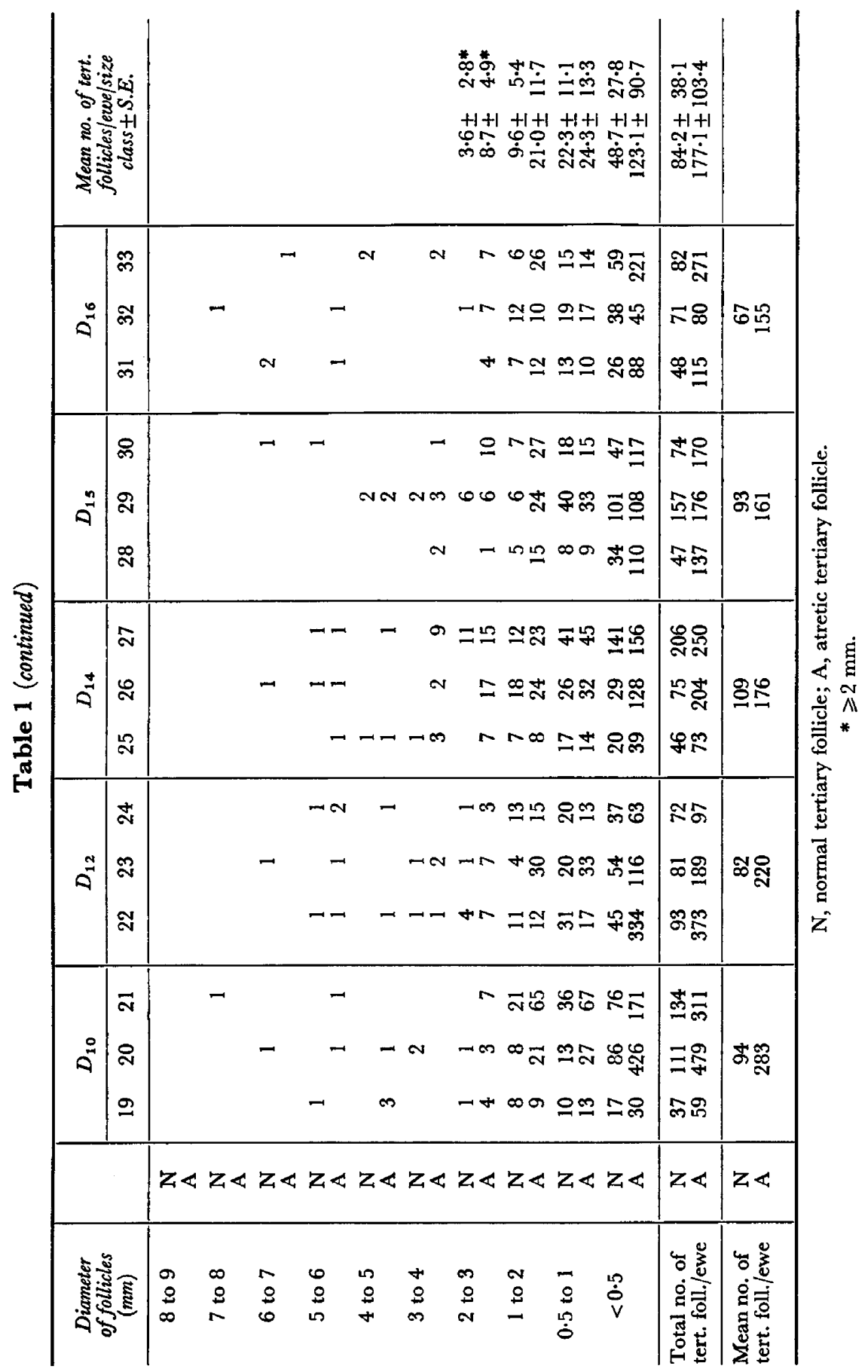




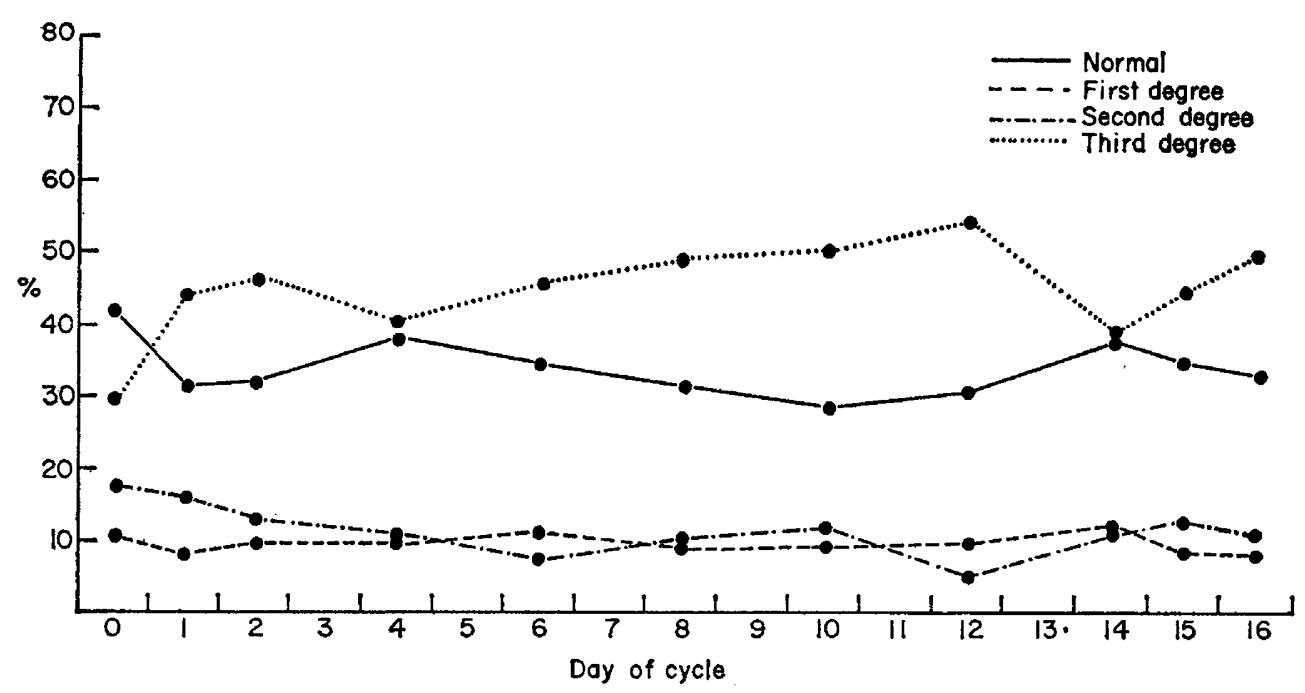

Text-Fig. 1. Mean percentages of normal and atretic (first, second and third degree) tertiary follicles per ewe on various days of the oestrous cycle.

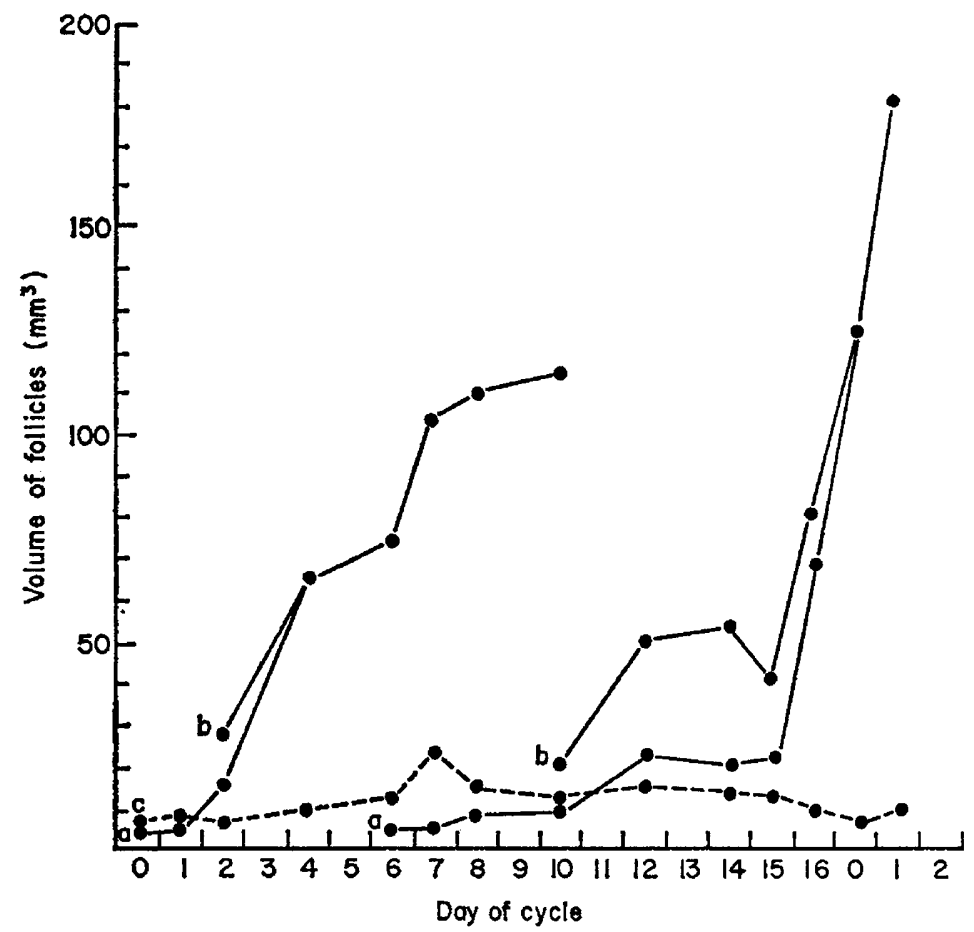

TEXT-FIG. 2. Mean volume of normal $(\longrightarrow)$ and atretic (-- -) sheep follicles of $\geqslant 1 \mathrm{~mm}^{3}$ in the first and second growth wave during the oestrous cycle ( $\mathrm{a}$ and $\mathrm{c}$ represent follicles of $\geqslant 1 \mathrm{~mm}^{3}, b$ and $d$ represent follicles of $\geqslant 20 \mathrm{~mm}^{3}$ ). 
Growth waves of follicles of $\geqslant 1 \mathrm{~mm}^{3}$ in volume during the oestrous cycle

The average volumes of normal (138) and atretic (310) tertiary follicles of $\geqslant 2 \mathrm{~mm}$ in diameter in the ovaries of thirty-nine ewes on various days of the oestrous cycle are illustrated in Text-fig. 2. During the cycle, two growth waves of normal follicles of $\geqslant 1 \mathrm{~mm}^{3}$ occurred. The first was seen from Day 1 to Day 10 , the second from Day 6 to Day 1 of the next cycle. When only large normal follicles of $\geqslant 20 \mathrm{~mm}^{3}$ were taken into account, the first wave lasted from Day 2 to Day 10 and the second from Day 10 to Day 1 . The mean volumes of the follicles belonging to the first growth wave was $6 \mathrm{~mm}^{3}$ on Day $1 ; 78 \mathrm{~mm}^{3}$ on Day 6 and $136 \mathrm{~mm}^{3}$ on Days 9 to 10 . On these days, an average of six (three to nine), two and one normal follicle(s) per ewe were involved, respectively.

Atretic processes caused the decrease in the number of follicles and after Day 10, the last follicle also became atretic.

The mean volume of the follicles belonging to the second growth wave was $4 \mathrm{~mm}^{3}$ on Day $6,7 \mathrm{~mm}^{3}$ on Day $10,22 \mathrm{~mm}^{3}$ on Day 15 and $185 \mathrm{~mm}^{3}$ on Day 1 of the next cycle. The number of normal follicles per ewe between Days 6 and 15 ranged from one to twelve. On Days 16 and 0 , six ewes showed a total of eleven normal follicles belonging to this second growth wave. Thus, during the second growth wave also, a number of normal follicles became atretic, though no initial atresia was seen in the largest normal follicle(s) of the second growth wave. In two ewes investigated on Days 10 and 15 , there was not a single normal follicle of $\geqslant 1 \mathrm{~mm}^{3}$ present. The large follicles of the ewe slaughtered on Day 15 already showed very advanced atresia. From these investigations, it would appear that all large follicles of Day 16 and of Day 0 are destined to ovulate after a rapid increase in their volume on these days.

The differences between the two growth waves can be summarized as follows: (a) the volumes of the follicles of the first wave increased more gradually than those of the second wave; (b) at the end of the first growth wave, there was only one large normal follicle per ewe, whereas at the end of the second wave, usually two were found (five out of six ewes); (c) at the end of the first growth wave, no preovulatory growth-spurt was observed. It existed, however, at the end of the second growth wave; (d) the last follicle of the first wave disappeared by atresia and the last one(s) of the second wave by ovulation.

The change in the mean volume of the atretic tertiary follicles did not show a systematic variation during the cycle. Atretic follicles of $\geqslant 50 \mathrm{~mm}^{3}$ were only observed from Days 5 to 15 . These originated primarily from large normal follicles of the first growth wave which were still detectable as atretic follicles of $\geqslant 20 \mathrm{~mm}^{3}$ on Day 1 of the next cycle.

During the middle part of the cycle, it was not difficult to differentiate between the normal follicles of the two growth waves. The volume was greater and the thickness of the membrana granulosa was thinner in the follicles of the first growth wave from Day 7 onwards.

\section{DISCUSSION}

Since systematic counts of normal and of atretic tertiary follicles have not previously been reported for sheep, there are no data for direct comparison. 
Statistical evaluation for variation in total numbers and numbers in the various size classes of normal and of atretic tertiary follicles between cycle days revealed that in the thirty-three ewes, the individual differences were so great that they overshadowed the differences between days. Thus, it seems likely that, during the oestrous cycle, the tertiary follicle population is constant and that an equilibrium exists between the production of follicles in a certain size class and their disappearance from that class, either by passing to a higher size class or by atresia. In cattle, Rajakoski (1960) and Choudary, Gier \& Marion (1968) were also unable to find a systematic variation in tertiary follicles during the cycle.

Although there was no correlation between the day of the cycle and the number of normal follicles of $\geqslant 2 \mathrm{~mm}$ in diameter, there was a definite growth pattern of these follicles during the cycle. This became quite clear when the volumes instead of the diameters were compared (Text-fig. 2). This finding is in agreement with that of Rajakoski (1960), who found that during the bovine oestrous cycle, follicles of $\geqslant 5 \mathrm{~mm}$ in diameter went through two growth waves; the first from Days 1 to 12 and the second from Days 12 to 0 . Our findings differ from the observations of a number of authors (Santolucito, Clegg \& Cole, 1960; Robertson \& Hutchinson, 1962; Marincowitz, 1964; Hutchinson \& Robertson, 1966). They believed that in sheep the follicles destined to ovulate were already enlarged at the beginning of the cycle and that they underwent little increase in size until preovulatory enlargement. These investigators studied follicular development by macroscopic techniques only.

Thus, during the second half of the oestrous cycle, they were unable to distinguish between the atretic follicles of the first growth wave and the normal follicles of the second growth wave.

Smeaton \& Robertson (1971) studied the development of individual Graafian follicles during the cycle by injecting them with $2 \mu \mathrm{l}$ Indian ink. They concluded that there were at least three phases of follicular growth and atresia during each oestrous cycle. They found that in six out of seven ewes, the large follicles $(5 \mathrm{~mm}$ in diameter or more) on Days 6 to 9 and Days 13 to 15 (Day $1=$ onset of oestrus) did not ovulate but regressed. The follicle which finally ovulated, grew rapidly to the $5-\mathrm{mm}$ size during the 36 to $48 \mathrm{hr}$ between the regression of the corpus luteum and the onset of oestrus. In the present work, we were not able to discover a third growth wave starting 36 to $48 \mathrm{hr}$ before the onset of oestrus. If such a wave existed, there would be atresia in the largest 'normal' follicles on Days 13 to 15 . With the exception of one ewe, this was seen only in follicles smaller than any of the normal ones of the second growth wave. When we detected large regressing follicles during this period, they already showed advanced cystic atresia. These follicles must therefore result from the normal follicle(s) of the first growth wave which become atretic after Day 10.

Although it is now generally accepted that the growth of follicles is dependent on gonadotrophic hormones, it seems likely that the two growth waves of large follicles may be controlled by circulating levels of progesterone. This may be mediated by a direct effect on the large follicles (Ginther, 1971) or indirectly by interfering with gonadotrophic hormones in the ovary (Llerena, Guevara, Lobotsky, Lloyd \& Weisz, 1969). The end of the first growth wave occurs when the progesterone level has reached its maximum (Thorburn, Bassett \& Smith, 
1969; Stabenfelt, Holt \& Ewing, 1969). The large normal follicles of the second growth wave show only a slow increase in volume until Day 16 but a rapid increase (preovulatory growth spurt) thereafter (see Pl. 1, Fig. 2). These changes in follicular development during the second growth wave appear to be correlated with high progesterone levels up to Day 14, and a decline rapidly thereafter which results in a very low concentration on Days 16 and 0 (Moore, Barrett, Brown, Schindler, Smith \& Smyth, 1969).

For a better understanding of the mechanisms controlling the waves of follicular development, it is clearly necessary to study more thoroughly the relationships between the morphological and endocrinological changes during the cycle under experimental conditions.

\section{AGKNOWLEDGMENTS}

The authors are grateful to Dr O. E. B. Gebhart, Dr Mary F. Hay and Dr R. M. Moor for their help and valuable criticism in the preparation of this paper.

\section{REFERENCES}

Ghoudary, J. B., Gier, H. T. \& Marion, G. B. (1968) Cyclic changes in bovine vesicular follicles. $\mathcal{F}$. Anim. Sci. 27, 468.

GiNTHER, O. J. (1971) Influence of progesterone and number of corpora lutea on ovaries in sheep. $\mathrm{Am}$. 7. vet. Res. 32, 1987.

Grant, R. (1934) Studies on the physiology of reproduction in the ewe. Trans. R. Soc. Edinb. 58, 1.

Hutchinson, J. S. M. \& Robertson, H. A. (1966) The growth of the follicle and corpus luteum in the ovary of the sheep. Res. vet. Sci. 7, 17.

Llerena, L. A., Guevara, A., Lobotsky, J., Lloyd, G. W. \& Weisz, J. (1969) Concentration of luteinizing and follicle-stimulating hormones in peripheral and ovarian venous plasma. $\mathcal{J}$. clin. Endocr. Metab. 29, 1083.

Marincowrtz, G. (1964) Follikel stimulerende hormoon en interstisieelsel stimulerende hormoon in die hypofysevoorlob van die ooi en die voorkoms van oestrus en ovulasie. Thesis, School of Agricultural Science of Wageningen.

Moore, N. W., Barrett, S., Brown, J. B., Schindler, J., Smith, M. A. \& Smyth, B. (1969) Oestrogen and progesterone content of ovarian vein blood of the ewe during the oestrous cycle. F. Endocr. 44, 55 .

QuinLAn, J. \& MARÉ, G. S. (1931) The physiological changes in the ovary of the Merino sheep in South Africa, and their practical application in breeding. In: 17th Report to the Director of Veterinary Research and Animal Industry, Union of South Africa, p. 603.

Rajakoski, E. (1960) The ovarian follicular system in sexually mature heifers with special reference to seasonal, cyclical and left-right variations. Acta endocr., Copenh. Suppl. 52.

Robertson, H. A. \& Hutchinson, J. S. M. (1962) The levels of FSH and LH in the pituitary of the ewe in relation to follicular growth and ovulation. F. Endocr. 24, 143.

Santolucito, J. A., Glegg, M. T. \& Cole, H. (1960) Pituitary gonadotrophins in the ewe at different stages of the estrous cycle. Endocrinology, 66, 273.

Smeaton, T. C. \& Robertson, H. A. (1971) Studies on the growth and atresia of Graafian follicles in the ovary of the sheep. F. Reprod. Fert. 25, 243.

Stabenfelt, G. H., Holt, J. A. \& Ewing, L. L. (1969) Peripheral plasma progesterone levels during the ovine estrous cycle. Endocrinology, 85, 11.

Thorburn, G. D., Bassett, J. M. \& Smith, J. D. (1969) Progesterone concentration in the peripheral plasma of sheep during the oestrous cycle. $\mathcal{F}$. Endocr. 45, 459. 